\title{
Supply chain management practices, innovation capabilities and operational performance: An empirical evidence from the FMCG sector
}

\author{
Amr Elfawal \\ Henkel Regional Senior Director, Graduate School of Business \\ Arab Academy for Science Technology \& Maritime Transport, Egypt \\ Mohamed A. Ragheb \\ Graduate School of Business \\ Arab Academy for Science Technology \& Maritime Transport, Egypt \\ Riham Adel \\ College of Management \&Technology \\ Arab Academy for Science Technology \& Maritime Transport, Egypt
}

\section{Keywords}

SCMP, Innovation Capabilities, Operational Performance, FMCG.

Abstract

The purpose of this paper is to propose a conceptual framework for examining the impact of innovation and supply chain management practices on operational performance of FMCG organizations within the Middle East and North Africa Region. The quantitative data is collected through 519 questionnaires as the research population refers to Henkel across the Middle East and North Africa. Structural Equation Modelling (SEM) is adopted to examine the causal relationships between' supply chain management practices, innovation capabilities and operational performance. The findings of this paper reveal that Supply chain management practices have a positive influence on operational performance. Supply chain management practices have a positive influence on innovation capabilities. The direct effect between innovation capabilities and operational performance is statistically significant. However, the results of the mediation effect indicate that there is partial mediation effect of the innovation capabilities between supply chain management practices and operational performance.

\section{Introduction}

Innovation is considered a key factor in business performance (Panayides and Venus Lun, 2010). One approach to innovate is to think of one's customers, suppliers, and more commonly one's partners. For an organization, this alludes the management of its inter-organizational relationships. Away from the traditional sight of technological and product innovation, organizations need to develop "managerial" innovations. Such innovations can be a significant source of competitiveness for organizations (Birkinshaw et al., 2008). Damanpour and Aravind (2012) recommend investigation of external conditions and internal processes that facilitate the introduction of compositions of innovation types across organizational units and over time.

Fast-Moving Consumer Goods (FMCGs) supply chains produce innovative ideas and perform as benchmarked frameworks for other industries, because of their high capacities of product flows, close communication with their customers, less multifaceted manufacturing processes besides the dominance of retailers (to some extent). Nevertheless, a very complex underlying supply chain system supports this industry. Despite the innovative ideas engendered, FMCG supply chains are faced with exceptional challenges and issues (Kumar, 2002). FMCG industry is a speedy, agile industry with an extensive range of products(ibid).

Due to Roy and Wilkinson (2004) innovative supply chain concentrates on persistent improvement of the supply chain cost structure throughout standardization and simplification. This lowers materials costs and improves customer satisfaction. With innovative supply chain, a company can collaborate with business partners throughout integration of data and processes. This improves information sharing and hence minimizes communication costs leading to superior decision making. This enables the company create alignment around common business objectives that conceive new tools, methodologies, and processes to advance efficiency and performance of the company. Batenburg and Rutten (2003) elaborated 
that innovative supply chain practices ensures continuous development of supply chain functions in which leads to competitive advantage and differentiation of products as well as services to meet the rising and changing needs of customers.

Moreover, if there are long-term market changes, efficiency of SC is not easily achieved. Therefore, a corporate must have innovation capabilities to implement the appropriate strategies needed for uncertain altering environments (Liao et al., 2010). Based on the above, the overall aim of this thesis is to make generalized assumptions about the impact of innovation and supply chain management practices on operational performance of FMCG organizations within the Middle East and North Africa Region. In order to fill the knowledge gap and achieve the aim, four objectives were formulated namely:

1- To examine the relationship between supply chain management practices and operational Performance of FMCGs.

2- To investigate the relationship between supply chain management practices and innovation Capabilities of FMCGs.

3- To examine the relationship between innovation capabilities and operational Performance of FMCGs.

4- To investigate the mediation role of innovation capabilities between supply chain management practices and operational Performance of FMCGs.

\section{Literature Review}

\section{Supply Chain Management Practices (SCMP)}

Lavastre et al., $(2011,2014)$ defined innovative supply chain practices as :"The development and implementation of tools and methodologies by and between partners of the same supply chain, that do not previously exist within the company or its subsidiaries, and which aim to address a variety of issues related to quality, cost and timeliness These practices are generally part of a policy of continuous improvement and value creation for the customer, and increased company and entire supply chain performance" . A 2005 OECD report highlighted the need to investigate organizational innovations for two main reasons: On one hand, they frequently convoy product and / or technology innovations. On the other hand, they are enhanced to create a competitive advantage that is easily defensible, durable, or hard to imitate by competitors (Leroy et al., 2013). In addition to that, the report recommended conducting study to characterize this type of innovation, but also to assess its economic impact on businesses.

The deployment context of an SCMP is crucial. Indeed, unlike an invention in which it refers to the creation of something new, innovation is the financial and economic translation of an invention. Therefore, it requires a transformation and appropriation by the firm that must encompass the innovation in its organization and strategy, also match market expectations (Lin et al., 2010). The literature of this topic, however, remains relatively limited and fragmented and some researchers lament those investigations in the field of logistics and SCMP largely disregard the concept of innovation (Flint et al., 2005). From this viewpoint, there is a crucial need for studying innovation in inter-organizational practices throughout questioning information systems (Bello et al., 2004), expected benefits (Wagner, 2010) and collaborative relations between supply chain partners (Soosay et al., 2008). Despite the fact that many measurement scales have been developed in the region of innovation and SCM, relatively few have investigated innovative practices in this domain. Flint et al. $(2005,2008)$ presented a measuring instrument issued from the literature to investigate the process of innovation in the downstream supply chain. Knight and Cavusgil (2004) examined the capacity in a company for product innovation at the research and development (R\&D) level.

The researcher subscribes to this sight and propose completing knowledge within the field of innovation via questioning innovative supply chain practices in the domain of SCM. In addition to that, the literature review conducted for this research study concentrated on the concept of innovation applied to the field of SCM innovation and particularly in Fast Moving Consumer Goods (FMCG). There are various innovative supply chain management practices used by firms to gain competitiveness in terms of improved customer satisfaction and cost effectiveness, hence improve the operational performance. These practices include mass customization, e-procurement, integration, reverse logistics and just in time. 
Mass Customization: Mehra and Inman (2014) emphasized that customization is an innovative supply chain practice that involves tailoring products and services due to the specific customer needs. The systems aggregate such type of individual orders along with schedules picking, assembly or production. This improves efficiency ever since the customers can conveniently get goods and services that suites their needs. Dowlatshahi (2012) asserted that mass customization is a common practice amid the developed countries, customer desires keep on changing hence it is crucial for the companies to cope with the market demand. This can be achieved throughout producing and designing competitive products that meet the subsequent attributes namely: flexibility, cost effectiveness convenience, and improved value. Various benefits of mass customization are that it decreases stock-out costs and holding costs of the company since products are produced upon requisition by customers.

E-procurement: E-procurement is the usage of internet-based information communication technologies (ICTs) to perform individual or all stages of procurement process encompassing sourcing, ordering, negotiation, receipt as well as post purchase review (Croom and Brandon-Jones, 2004). There are a variety of forms of e-procurement that focus on many stages of procurement process such as etendering, reverse auction, e-marketplace, and e-catalogue purchasing. In addition to that E-procurement serves what is called end-to-end solution that integrates and streamlines lots of procurement processes throughout the firm. Robinson (1999) mentioned in Shalakha, 2015) identified the significance of eprocurement in improved efficiency, cost saving, and single data entry. The use of e-procurement system makes it possible to monitor and measure orders along with their details for instance: removal of nonvalue adding activities and improved standardization of processes. This also minimizes the paperwork and improves efficiency within order approval and processing of documents.

Integration: One of the information systems that helps firms to integrate their functions and activities encompass: Electronic Data Interchange (EDI) which is a system that integrates business processes therefore provide long-term client and supplier relationships a true spirit of partnership. Watson and Zhang (2005) argued that an ERP package is a database which allows a firm to develop and store data that can be utilized in all the applications. This advances information sharing crosswise the supply chain partners as well as minimizes communication costs leading to improved supply chain operational performance.

Just in Time: Mehra and Inman (2014) defined just-in-time (JIT) as an operating concept deliberated to eliminate waste. The objective for JIT is to produce products and services without wastage. This is achieved by experimenting each step in a process to find out if it adds value to the product or to the service. Song and Zipkin (2011) explained that JIT system enables companies to operate efficiently with the lowest number of resources, consequently, minimize inventory levels, improve quality, and provide greatest motivation to solve problems where and when they take place. Other benefits of this concept are that it minimizes the cycle time while products are produced upon the requisition of the customer. This augment cost savings and competitiveness since customers get the precise product in terms of quality, quantity, and value based on their needs.

Reverse Logistics: Reverse logistics is part of the innovative supply chain practices that aids companies in costs savings throughout use of environmentally friendly products which need minimal processing compared to mechanize a completely new product. Jack et al. (2010) explained that reverse logistics enables the company to improve its agility. Some companies grasp more inventories compared to the market demand. If they can swiftly disposition this material, and possibly even accept some of its cost back, their ability to be doing well in the marketplace enlarges.

\subsection{Innovation Capabilities}

There has been an increasing interest in the study of innovation capability in supply chain context in recent times (Delbufalo et al., 2015; Iddris et al., 2014). Innovation capability in this research encompasses three dimensions namely: Dynamic Capability, Knowledge Capability and collaborative capability.

\section{Dynamic Capability (DC)}

The concept of Dynamic Capability (DC) was first presented by Teece et al. (1997), it has received a wide-ranging of attention, and mostly been used for clearing up how firms gain competitive advantage throughout the dynamic market environment. Jiang (2011) believed that SCDC is the change of the 
capability of supply chains by extending the DC from single organizations to the supply chain. Pagell and $\mathrm{Wu}(2009)$ proposed that resource renovation and integration refers to the change of process connection, original organization and business field to adjust to the dynamic change of environment. Regarding the measures of SCDC, Jiang (2011) also stated that SCDC includes: learning capability, coordination capability, operation capability, and reconstruction capability. Wu (2010) measured the SCDC from three dimensions: learning capabilities, Resource integration capabilities, and resource reconstruction capabilities. Similarly, Caloghirou et al. (2004) measured the SCDC from another three dimensions: coordination ability, learning ability, and change ability (Shan et al, 2020).

\section{Knowledge Capability}

knowledge is compatible with the conventional definition and includes diverse kinds of knowledge for instance, explicit and tacit knowledge, information as well as knowhow of the management, technological, and marketing knowledge. Three sub capabilities: Knowledge Acquisition Capability (KAC), Knowledge Generation Capability (KGC), and Knowledge Combination Capability (KCC) characterize the three dimensions of knowledge-based capabilities.

KAC. Knowledge acquisition means the organization's ability to identify and acquire practical external knowledge. The knowledge of organization exists in two special forms: explicit and tacit knowledge (Kogut and Zander, 1992). Therefore, efforts spent on knowledge acquisition encompass creative searching and strategic sense-making also were greatly prejudiced by manager's logic pattern and behavior (Pandza and Thorpe, 2009).

KGC. Generation denotes a firm's capability to develop and refine processes that facilitate generating new knowledge. The processes include internal $R \& D$ and knowledge creation throughout external venturing (Wadhwa and Kotha, 2006). Rosenberg (1982) pointed out very early in his classical research that "reliance on borrowed technology (by developing countries) perpetuates a posture of dependency and passivity", catching-up corporations without KGC have experienced the "acquisition-lag outacquisition" in countless later comer economies (Rosenberg, 1982).

KCC. Combination capability is the firm's talent to integrate and apply internal along with external knowledge. Kogut and Zander (1992) suggested that organizations learn new skills by recombining their existing capabilities. As discussed above, the three dimensions work together. They tend to be path dependent, develop cumulatively, and build on each other to figure integrated dynamic capabilities of the company.

\section{Collaborative Capabilities}

Delbufalo et al. (2015) focused on the contribution of supply network to a focal organization's competitiveness by investigating the relationship among supply network structure and collaborative capability. Tan et al. (2015) explored the use of big data for instance: tweets, click stream, videos, and other unstructured sources - to enhance supply chain innovation collaborative capability. They proposed analytical infrastructure for serving supply chains gather big data in order to enhance collaborative capability. Shan et al. (2020) studied the impact of SC collaborative innovation on the sustainable development. The results showed that: (1) Three modes of SC collaborative innovation namely: (management collaborative innovation, technology collaborative innovation, and market collaborative innovation) and they have different effects on SCDC and performance. (2) SCDC mediates the relation between collaborative innovation and performance. (3) SC technology collaborative innovation has the greatest impact on performance.

\subsection{Operational Performance}

The performance can be defined as "A set of metrics used to quantify the efficiency and effectiveness of supply chain processes and relationships, spanning multiple organizational functions and multiple firms and enabling supply chain orchestration" (Maestrini et al., 2017). The main objective of every organization is to enhance the performance but firstly they should find a measurement tool to measure it accurately (Gunasekaran and Kobu, 2007). Gunasekaran et al. (2004) illustrated a comprehensive framework for performance measurement divided into strategic, tactical in addition to operational processes. Six categories encompassed namely: metrics for order planning; measures and metrics at production level; evaluation of supply link; measuring customer service and satisfaction; evaluation of delivery link; and 
supply chain and logistics. Panayides and Lun (2010) recognized delivery reliability, lead times, responsiveness, cost reduction, conformance to specifications and process improvements in addition to time-to-markets as constituents of Supply Chain Performance (Shan et al., 2020).

\subsection{The relationship between Supply Chain Management Practices and Operational Performance}

The relationships that company develop with their suppliers and customers can eventually be considered as competitive tools which contribute to enhanced organizational performance. In this context, Huang and Liu (2014) examined the relation between supply chain integration and supplier's performance of manufacturing companies. Findings revealed that the adoption of modern technologies led to superior organizational performance. Due to Roy and Wilkinson (2004) innovative supply chain concentrates on relentless improvement of the supply chain cost structure throughout standardization and simplification. This lowers materials costs and improves customer satisfaction. Batenburg and Rutten (2003) elaborated that innovative supply chain practices ensures continuous development of supply chain functions in which leads to competitive advantage and differentiation of products as well as services to meet the rising and changing needs of customers.

\subsection{The relationship between Supply Chain Management Practices and Innovation Capabilities}

Supply Chain Innovation Capabilities describes the intra and inter-organizational competence within a SC to cooperate, in order to identify, develop, and implement innovative, solution-oriented actions so as to address new or formerly unsolved problems (Storer et al., 2007). Due to Savory (2006) supply chains do not only need to reconfigure current capabilities and resources, but they must also give up old configurations in implementing the newly reconfigure capabilities. To understand the relationships between innovation capabilities and innovative practices, it is significant to recognize what Prieto and Easterby-Smith (2006) observed as the link between knowledge and dynamic capabilities. They preserved that the dynamic capabilities that enable also underpin long-term continuing renewal require both exploitation of current knowledge and exploration of "new knowledge-based competences". New knowledge and technologies, in addition to existing knowledge and technologies, after a while translate into meaningful practices, operational processes, and systems.

\subsection{The relationship between Innovation Capabilities and Operational Performance}

Supply chain integration and performance are topics that have been extremely researched and various studies showed that there is a positive relationship between both of them (Devaraj et al., 2007 and Wong et al., 2011). Short-term supply and demand imbalances could have a negative effect on SC efficacy. Moreover, if there are long-term market changes then, the efficiency of SC is not easily achieved. Therefore, a company must have innovation capabilities to implement the appropriate strategies needed for uncertain altering environments (Liao et al., 2010).

In order to enhance SC innovation capabilities, a company has to develop a responsive SC throughout increased collaboration with other firms in supply chains (Kim and Lee ,2010). The dynamic capabilities theory was applied to SC mainly concentrated on the bullwhip effect that gained from the lack of information sharing amongst companies in the supply chain. likewise, to supply chain innovation capabilities, successful companies create supply chains that are: adaptable, agile, and aligned, which is termed Triple-A of SC by Lee (2004). An organization implementing Triple-A SC responds to altering markets, coordinates business processes through sharing information, risks as well as benefits, and enhances competitiveness of SC partners on top of improving the operational performance. 


\section{Research Framework}

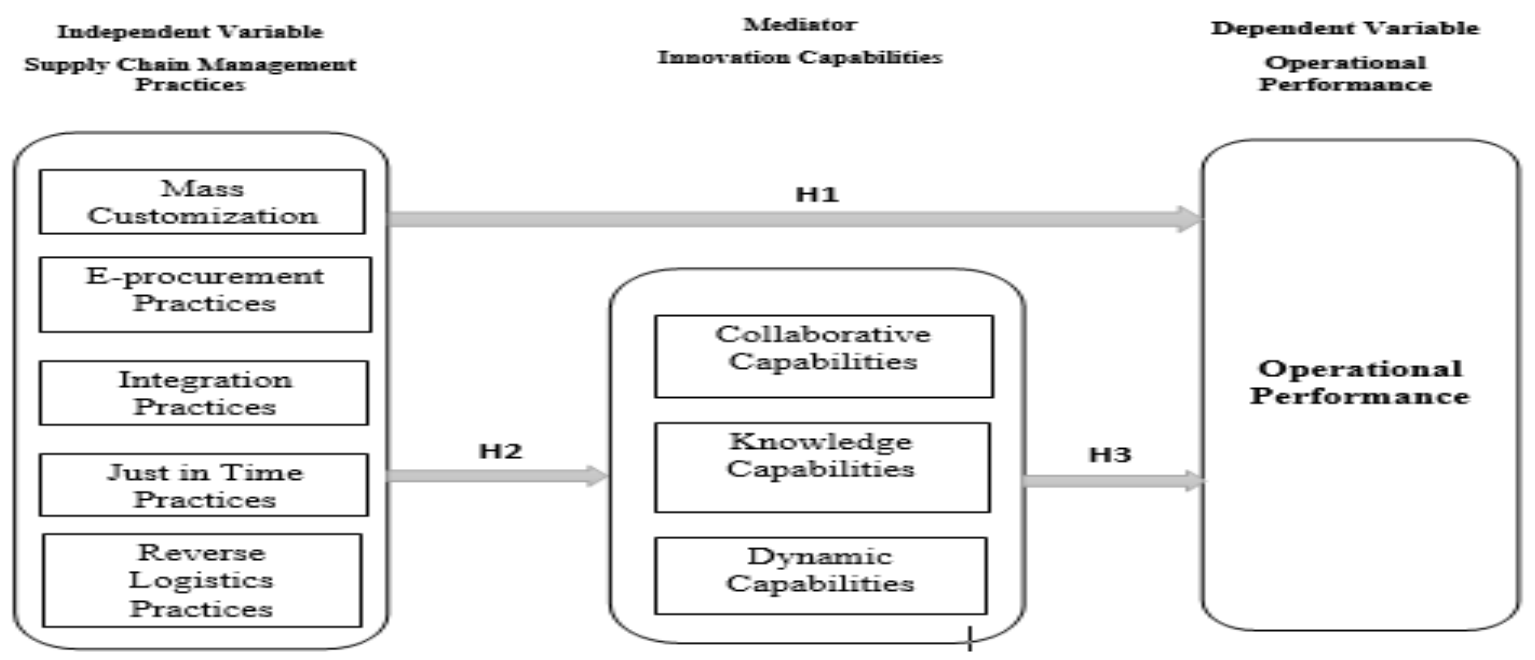

Figure 1: Conceptual Framework

\section{Research Hypotheses}

H1: Supply chain management practices have a positive influence on operational performance.

$\mathrm{H} 2$ : Supply chain management practices have a positive influence on innovation capabilities.

H3: Innovation Capabilities have a positive influence on operational performance.

H4: innovation capability mediates the relationship between supply chain management practices and Operational Performance.

\section{Research Methodology}

\subsection{Research Design}

For describing trends and explaining the relationship among variables found in the literature, the research will follow the quantitative research to conduct this inquiry. The researcher' specifies narrow ${ }^{\prime}$ questions, locates' or develops' instruments to gather data to answer' the questions, and analyses numbers from the instruments, using statistics.

\subsection{Population and Sampling}

Population of a research is defined by Saunders' et al., (2016) as the collection' of all items whether of objects or of events or of people, that are to be considered in a given' problem situation. For the purpose' of this research, the research population refers' to Henkel employees across the Middle East and North Africa. A questionnaire is conducted to collect data online via google forms. The research questionnaire' was administered' to eight hundred (800) respondents, 566 questionnaires representing $70.7 \%$ were returned, and 47 questionnaires representing $5.8 \%$ were incomplete or ineligible or refusals and $234(29.2 \%)$ were not reached. There were 519 acceptable responses, a response rate $65 \%$, which is highly adequate for the nature of this study. In this' Research Paper, the Amos 26.0 software' package was used' to perform' the structural equation' modelling (SEM) to investigate' the inter-relationships between the four constructs of the hypothesized model. The SEM is a statistical' technique' that allows assessment' of both direct' and indirect' effects of each variable' on the other' variables. Hypotheses Testing Following a confirmatory factor analysis, the valuation of the structural model through testing of the hypotheses underlying the research model is conducted.

\section{Results and Findings}

According to Hair et al. (2019) SEM is a multivariate technique which combines multiple regression with confirmatory factor analysis (CFA) to examine the series of dependence relationship simultaneously of the hypothesized model. SEM has two mechanisms, namely measurement model, and structural model. The measurement model is basically meant for the reliability and validity of the latent variables and 
observed variables, and the structural model is concerned with the path strength and relationship among the latent variable.

The estimations of the parameters and the overall fit index of the measurement model are based on the maximum likelihood (ML) method. The basic conditions assumed for the use of ML estimation are met or closely approximated in the study (Byrne, 2016). Further, the sample is sufficiently large $(\mathrm{n}=519)$, over the recommended size of 384 cases (Medsker et al., 1994), the scale of observed variables is continuous, and no violations of multivariate normality are found in the survey responses.

The 8 latent variables are measured by 51 observed variables. The level of internal consistency for each construct was acceptable, with the standardized loading ranging from 0.630 to 0.864 which exceeded the minimum hurdle of 0.50. In a Confirmatory' Factor Analysis (CFA), the researcher' can assess the contribution' of each scale item as well as incorporate how well the scale' measures the concept (reliability). The scales are then integrated into the estimation' of the relationships between dependent and independent' variables in the structural model. This procedure is similar to performing a factor analysis of the scale items and using the factor scores in the regression (Hair' et al., 2019).

Composite reliability $(\mathrm{CR})$ is used to measure the reliability of a construct in the measurement model. CR is a more presenting way of overall reliability, and it determines the consistency of the construct itself (Hair et al., 2019). Table1 shows the CR. So, it clearly identified that in measurement model all construct have good reliability.

Measurement items have standardized loading estimates of 0.5 or higher (ranging from 0.630 to 0.864 at the alpha level of 0.05 , indicating the convergent validity of the measurement model. Discriminant validity shows the degree to which a construct is actually different from other constructs (Hair et al., 2019). The Average variances extracted (AVE) should always above 0.50 (Hair et al., 2019). Average variances extracted (AVE) is shown in table Table1. Overall, these measurement results are satisfactory and suggest that it is appropriate to proceed with the evaluation of the structural model.

Table 1 Model Validity Measures

\begin{tabular}{|l|c|c|}
\hline \multicolumn{1}{|c|}{ Variables } & CR & AVE \\
\hline Sales Orders Mass Customization & 0.899 & 0.689 \\
\hline E Procurement Practices & 0.836 & 0.560 \\
\hline Integration & 0.851 & 0.535 \\
\hline Just in Time & 0.875 & 0.701 \\
\hline Reverse Logistics & 0.757 & 0.509 \\
\hline Operational Performance & 0.900 & 0.532 \\
\hline Collaborative Capabilities & 0.876 & 0.502 \\
\hline Knowledge Capabilities & 0.843 & 0.556 \\
\hline Dynamic Capabilities & 0.899 & 0.560 \\
\hline
\end{tabular}

Model Fit: The model fit indices like the comparative fit index (CFI) Goodness of fit index (GFI), Normed fit index (NFI), Tucker lewis index (TLI) and Root mean square of error approximation (RMSEA) were chosen to evaluate the model fit (Thakkar 2020). The model fit indices of the structural model and the cut-off value of those fit indices are presented in Table. The goodness-of-fit statistics show that the structural model fit the data reasonably well.

Model estimating is commonly achieved in research using Weighted Least Squares (WLS), Generalised Least Square (GLS), Asymptomatic Distribution Free (ADF), and Maximum Likelihood Estimating (MLE) (Byrne, 2016). However, the estimations of the parameters and the overall fit index of the measurement model are based on the maximum likelihood (ML) method. The basic conditions assumed for the use of ML estimation (Byrne, 2016) are met or closely approximated in the study. Table (2) provides a measurement' model result - CFA 
Table 2: Measurement' model result

\begin{tabular}{|l|l|l|l|}
\hline Goodness of Fit Measures & Cut-off Value & Model Result & Remark \\
\hline$\square^{2}$ (Chi-Square) & $>0.05$ & 920.587 & accepted \\
\hline DF (Degrees of Freedom) & $\geq 0$ & 309 & accepted \\
\hline$\square^{2} /$ DF (Chi-Square/ Degrees of Freedom) & $\leq 3$ & 2.979 & accepted \\
\hline CFI (Comparative Fit' Index) & $\geq .90$ & .916 & accepted \\
\hline TLI (Tucker Lewis Index) & $\geq .90$ & .905 & accepted \\
\hline RMSEA (Root Mean' Square Error of Approximation) & $<.08$ & .062 & accepted \\
\hline
\end{tabular}

Model summary: The 8 factor was subjected to CFA using the AMOS software. DF was 309 (it should be more than 0 ), $\square^{2}$ /DF has a value of 2.979 , that is less than 2.0 (it should be less than or equal 2.0 or 3 ). The RMSEA was .062 (it should be less than 0.08). The TLI index was .905 which is very close to 1.0 (a value of 1.0 indicates perfect fit). The CFI was .916. All indices are close to a value of 1.0 in CFA, indicating that the measurement models provide good support for the factor structure determined through the CFA. Figure (2) shows a Structural Model (Final Result)

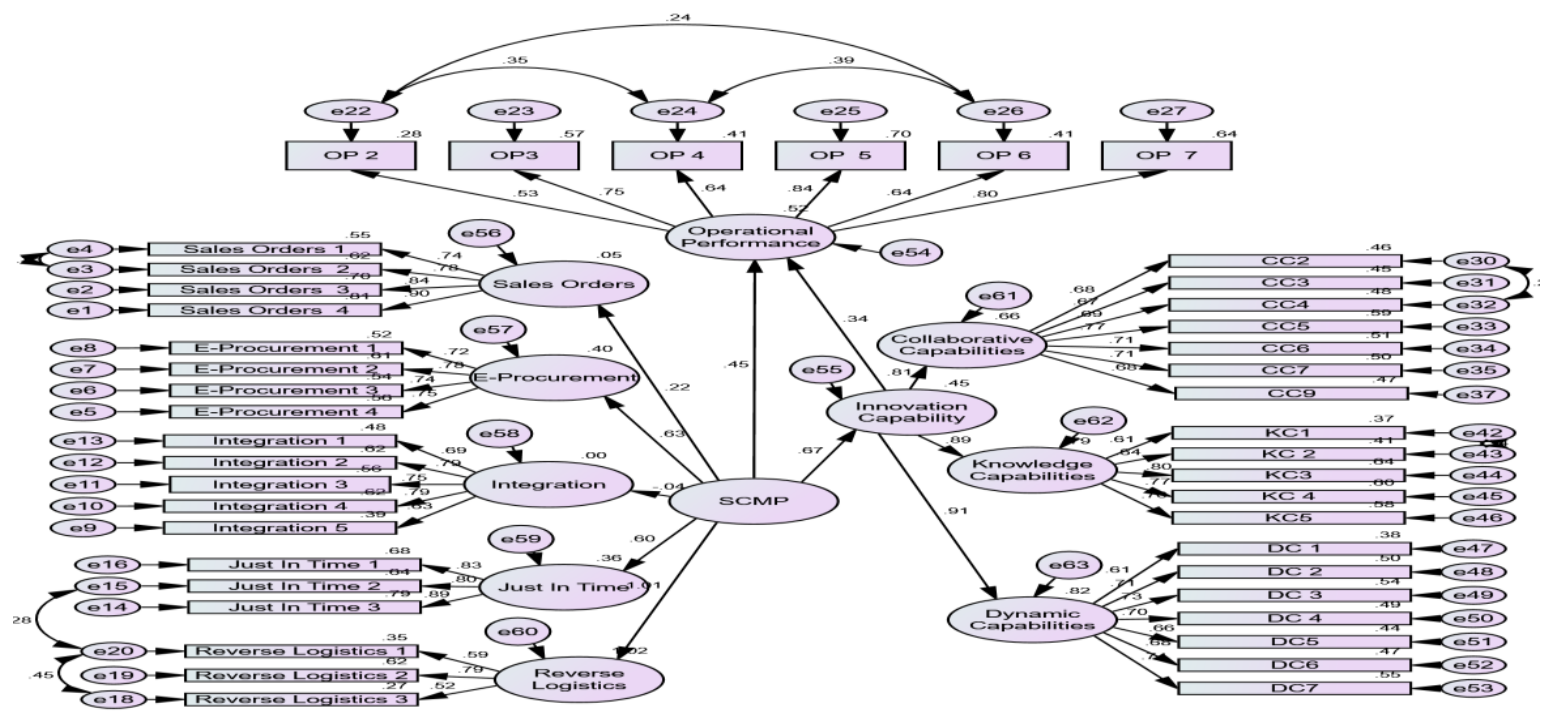

Figure 2: Structural' Model

The structural model validity - final Result:

Table (3) provides a structural' model (final Result)

Table 3: Structural' model - final Result

\begin{tabular}{|l|l|l|l|}
\hline Goodness of Fit (GOF) Measures & Cut-off Value & Model Result & Remark \\
\hline$\square^{2}$ (Chi-Square) & $>0.05$ & 2017.009 & accepted \\
\hline DF (Degrees of Freedom) & $\geq 0$ & 886 & accepted \\
\hline$\square^{2}$ /DF (Chi-Square/ Degrees of Freedom) & $\leq 3$ & 2.277 & accepted \\
\hline CFI (Comparative Fit' Index) & $\geq .90$ & .907 & accepted \\
\hline TLI (Tucker Lewis Index) & $\geq .90$ & .900 & accepted \\
\hline RMSEA (Root Mean' Square Error of Approximation) & $<.08$ & .050 & accepted \\
\hline
\end{tabular}


Model summary: The 11 latent factors was subjected to Structural' model using the AMOS software. DF was 886 (it should be more than 0), $\square^{2}$ /DF has a value of 2.277, that is less than 2.0 (it should be less than or equal 2.0 or 3). The RMSEA was .050 (it should be less than 0.08 ). The TLI index was .900 which is very close to 1.0 (a value of 1.0 indicates perfect fit). The CFI was 0.907 . All indices are close to a value of 1.0 in CFA, indicating that the measurement models provide good support for the factor structure determined through the CFA. See Table (3).

\section{Conclusion}

The purpose of this research paper is not descriptive or exploratory, but rather causal and explanatory. Furthermore, the researcher conducted a quantitative methodological phase of this paper. A questionnaire is used and includes three sections: first: supply chain management practices of FMCGs included (mass customization, E-procurement, integration, just in time, and reverse logistics). Second section: innovation capability included (collaborative capabilities, knowledge capabilities and dynamic capabilities). Third section: operational performance.

Population of a research is defined by Saunders' et al., (2016) as the collection' of all items whether of objects or of events or of people, that are to be considered in a given' problem situation. For the purpose' of this research, the research population refers' to Henkel across the Middle East and North Africa. The research questionnaire' was administered' to (800) respondents, 566 questionnaires representing $70.7 \%$ were returned, and 47 questionnaires representing $5.8 \%$ were incomplete or ineligible or refusals and $234(29.2 \%)$ were not reached. There were 519 acceptable responses, a response rate $65 \%$, which is highly adequate for the nature of this study. The proposed framework encompassed research variables: (supply chain management practices are considered' as the independent variable, innovation capability is considered as the mediator variable and operational performance is considered as the dependent variable. the researcher explores the analytical part performed to test the hypotheses performed to fulfill the research objectives.

Regarding the first objective: examining the relationship between supply chain management practices and operational Performance of FMCGs: According to the individual test of significance of the relationship between the variables. It reveals that, as expected Supply chain management practices have a positive influence on operational performance $(\beta=0.448, p=0.000, p<0.05)$. Therefore, (H1: Supply chain management practices have a positive influence on operational performance.) is supported. This finding is consistent with the result of Batenburg and Rutten (2003), Roy and Wilkinson (2004) and Huang and Liu (2014).

For the second objective: investigating the relationship between supply chain management practices and innovation Capabilities of FMCGs. The results showed that $\mathrm{H} 2$ : supply chain management practices have a positive influence on innovation capability. $(\beta=0.674, \mathrm{p}=0.000, \mathrm{P}<0.05)$ is supported, as it predicts that supply chain management practices have a positive direct effect on innovation capability. That result is consistent with Cohen and Levinthal (1990), Clark et al., (1992), Teece et al., (1997), Savory, (2006), and Prieto and Easterby-Smith (2006) who stated that supply chain management practices have a significant effect on innovation capability.

For the third objective: examining the relationship between innovation capabilities and operational Performance of FMCGs. pertaining to H3: innovation capability has a positive influence on operational performance) is supported as the result shows that $(\beta=0.340, \mathrm{p}=0.000, \mathrm{P}<0.05$, as it predicts that innovation capability has a positive direct effect on operational performance. That result is consistent with Lee, (2004), Devaraj et al., (2007), Liao et al., (2010) and Wong et al., (2011) who stated that innovation capability has a significant effect on operational performance.

For the fourth objective: investigating the mediation role of innovation capabilities between supply chain management practices and operational Performance of FMCGs. Findings revealed a statistically significant indirect impact of supply chain management practices through innovation capability $(\mathrm{P}=$ $0.004, \mathrm{P}<0.05)$. The results of the mediation effect indicate that there is partial mediation effect of the innovation capability between the relationship of supply chain management practices and operational performance. 
This research paper investigates the impact of supply chain management practices on operational performance of FMCG organizations as well as the mediating role of innovation capabilities using a hybrid scales embracing (the collaborative capabilities, knowledge capabilities and dynamic capabilities) used for the first time in the middle east and the research tried to fill the knowledge gap and did not use the traditional models. Supply chain management practices constructs explained $45.5 \%$ of innovation capability variance $\left(\mathrm{R}^{2}=0.455\right)$, Besides, supply chain management practices through innovation capability explained $52.1 \%$ of operational performance variance $\left(\mathrm{R}^{2}=0.521\right)$. Moreover, this paper gives insights to managers and practitioners to improve the operational performance using the supply chain management practices in addition to that the researcher shed the light on the role of supply chain innovation capability of FMCG organizations and recommends generalizing the findings of this paper be considered through managerial implementation processes in FMCG organizations.

\section{Research Limitations and Recommendations}

The researcher studies the FMCG supply chains industry and did not include other industries, it is recommended to conduct research on various industries to investigate if the innovation types introduced have same impact on supply chain management practices, innovation capabilities and performance. This research proposes the need to explore appropriate ways to increase the research and development programs in the FMCG industry that will establish a platform to build and foster innovation in supply chain management with the intention of enhancing value addition. A comparative study should be conducted with different settings both in the sub-region, the developed and emerging world to determine the innovative supply chain management practices used by FMCG companies globally besides their contribution to organizational performance. Then, findings can be compared with this dissertation and conclusion drawn based on concrete facts.

\section{References}

Batenburg, R. \& Rutten, R. (2003). Managing innovation in regional supply networks: a Dutch case of Knowledge industry clustering, Supply Chain Management: An International Journal, 83,263-270.

Bello, D. C., Lohtia, R., \& Sangtani, V. (2004). An institutional analysis of supply chain innovations in global marketing channels.Industrial Marketing Management, 33(1), 57-64.

Birkinshaw, J., Hamel, G. \& Mol, M.J. (2008). Management innovation. Academy of Management Review, 33(4),825845.

Byrne, B.M. (2016), 'Structural Equation Modelling with AMOS: Basic Concepts, Applications and Programming' (3rd ed), Lawrence' Erlbaum, Mahwah, NJ

Caloghirou, Y.; Protogerou, A.; Spanos, Y.; Papagiannakis, L. Industry-versus firm-specific effects on performance: Contrasting SMEs and large-sized firms. Eur. Manag. J. 2004, 22, 231-243.

Clark, P., Bennett, D., Burcher, P. \& Newell, S. (1992) The decision-episode framework and computeraided production management (CAPM). International Studies of Management \& Organization, 22, 69.

Cohen, W. \& Levinthal, D. (1990) Absorptive Capacity: A new perspective on learning and innovation. Administrative Science Quarterly, 35, 128-152.

Croom, S. \& Brandon-Jones, A. (2004). E-procurement: key issues in e-Procurement adoption and operation in the public sector, 13th International Purchasing \&Supply Education \& Research Association (IPSERA) Conference, April 4-7, Catania, Italy.

Damanpour, F. \& Aravind, D. (2012). Managerial Innovation: Conceptions, Processes, and Antecedents. Management and Organization Review, 8(2), 423-454.

Delbufalo, E., Adcroft, A. and Adcroft, A. (2015), "The inflence of supply network structure on fim's multiple innovation capabilities: a longitudinal study in the fashion industry",Management Decision, Vol. 53.

Devaraj S., Krajewski L., Wei J.C.(2007), Impact of ebusiness technologies on operational performance: The role of production information integration in the supply chain, Journal of Operations Management, 25, 6, 1199-1216.

Dowlatshahi, S. (2012). A framework for the role of warehousing in reverse logistics, International Journal of Production Research, 50(5):1265-1277.

Flint, D.J., Larsson, E., Gammelgaard, B., Mentzberg, J.T. (2005). Logistics Innovation: a customer value-oriented social process. Journal of Business Logistics, 26(1),113-147.

Flint, D.J., Larsson, E., Gammelgaard, B. (2008). Exploring processes for customer value insights, supply chain learning and innovation: An international study. Journal of Business Logistics, 28(1), 257-281.

Gina J. Medsker, Larry J. Williams and Patricia J. Holahan,(1984), " A Review of Current Practices for Evaluating Causal Models in Organizational Behavior and Human Resources Management Research", Vol. 20, No. 2,439-464 
Gunasekaran A and Kobu B (2007). Performance measures and metrics in logistics and supply chain management: A review of recent literature (1995-2004) for research and applications. International Journal of Production Research, 45(12): 2819- 2840.

Gunasekaran, A., Patel, C. and McGaughey, R.E. (2004), “A framework for supply chain performance measurement”, International Journal of Production Economics, Vol. 87 No. 3, pp. 333-347.

Hair, J., C.Black, W., J.Babin, B., \& E.Anderson, R. (2019). Multivariate Data Analysis (8th ed.). England: Pearson Prentice.

Huang, M.-C., \& Liu, T.C. (2014). Reexamining supply chain integration and the supplier's performance relationships under uncertainty, Supply Chain Management: An International Journal, 19, 1, 64-78.

Iddris, F., Awuah, G.B. and Gebrekidan, D.A. (2014), “The role of innovation capability in achieving supply chain agility", International Journal of Management \& Computing Sciences, Vol. 4, pp. 104-112.

Jiang, C. Supply Chain Dynamic Capability and Its Impact on Enterprise Competitive Advantage.Ph.D. Thesis, Jinan University, Jinan, Shandong Province, China, 2011.

Jack, .P. Powers, L. \& Skinner, L. (2010). Reverse logistics capabilities: antecedents and cost savings, International Journal of Physical Distribution and Logistics Management, 40(3):228-246

Jitesh J. Thakkar (2020), Structural Equation Modelling, Application for Research and Practice (with AMOS and R), Studies in Systems, Decision and Control, Vol 285, Springer Nature Singapore

Kim D., Lee R.P.(2010), Systems collaboration and strategic collaboration: Their impacts on supply chain responsiveness and market performance, Decision Sciences, 41, 4, 955-981, 2010.

Knight, G.A., Cavusgil, S.T. (2004). Innovation, organizational capabilities, and the born-global firm. Journal of International Business Studies, 35(2), 124-141.

Kogut, B. and Zander, U. (1992), "Knowledge of the firm: combinative capabilities, and the replication of technology", Organization Science, Vol. 3 No. 3, pp. 383-97.

Kumar, D. 2002. CPG Industry: Supply chain drivers using SCOR. Vision: The Journal of Business Perspective; Special Issue on Supply Chain Management. 7(1):99-10.

Lavastre, O., Ageron, B., Chaze-Magnan, L. (2014). La performance des Pratiques Inter-organisationnelles Innovantes (P2I) : Proposition d'un modèle conceptuel. Revue Française de Gestion, 40(239), 75-89.

Lavastre, O., Ageron, B., Spalanzani, A. (2011). De l'organisation industrielle au Supply Chain Management : un siècle d'innovations continues - Vers quelles pratiques des entreprises françaises en $2009 . \quad$ Revue Française de Gestion Industrielle, 30(3), 9-36.(16) (PDF) Innovative Supply Chain Practices (ISCP) in Supply Chain Management: Development and Validation of a Measurement Scale.

Lee H., The triple-A supply chain, Harvard Business Review, 102-112, 2004.

Le Roy, F., Robert, M., Giuliani, P. (2013). L'innovation managériale - Généalogie, défis et perspectives. Revue française de gestion, 39(235), 77-90.

Liao S., Wu C., Hu D., Tsui K.(2010), Relationships between knowledge acquisition, absorptive capacity and innovation capability: An empirical study on Taiwan's financial and manufacturing industries, Journal of Information Science, 36, 1, 19-35.

Lin, Y., Wang, Y. \& Chiahui, Y. (2010). Investigating the drivers of the innovation in channel integration and supply chain performance: A strategy orientated perspective. International Journal of Production Economics, 127(2), 320332.

Maestrini V, Luzzini D, Maccarrone P, and Caniato F (2017). Supply chain performance measurement systems: A systematic review and research agenda. International Journal of Production Economics, 183: $299-315$.

Mehra, S. \& Inman, R.A. (2014). Inventory management and efficiency of manufacturing firms, Journal of Operations Management, 1(2), $1-4$

OCDE. (2005). Manuel d'Oslo: Principes directeurs proposes pour le recueil et l'interprétation des données sur l'innovation technologique. Commission Européenne-Eurostat, 102p. http://www.oecd.org/fr/sti/ inno/2367523.pdf

Pagell, M.; Wu, Z. Building a more complete theory of sustainable supply chain management using case studies of 10 exemplars. J. Supply Chain Manag. 2009, 45, 37-56.

Panayides, P.M. \& Venus Lun, Y.H. (2010). The impact of trust on innovativeness and supply chain -performance. International Journal of Production Economics, 122(11), 35-46.

Pandza, K. and Thorpe, R. (2009), "Creative search and strategic sense-making: missing dimensions in the concept of dynamic capabilities", British Journal of Management, Vol. 20, supplement, pp. S118-31.

Prieto, I. \& Easterby-Smith, M. P. V. (2006) 'Dynamic capabilities and the role of organizational knowledge: an exploration. European Journal of Information Systems, 15, 500-510.

Rosenberg, N. (1982), Inside the Black Box: Technology and Economics, Cambridge University Press,Cambridge.

Saunders Mark, Lewis Philip, Thornhill Adrian, (2016), 'Research Methods for Business Students', Pearson Education Limited. 
Savory, C. (2006) Translating knowledge to build technological competence. Management Decision, 44, 1052-1075.

Shalakha, S.M. (2015). Innovative supply chain management practices and organizational performance of oil marketing companies in Kenya. Master of business administration, University of Nairobi. Available at: https://pdfs.semanticscholar.org/8e8d/9453fee1eb53995f9e0cc482415d4a211099.pdf

Shan,H., Li,Y., and Shi,J. (2020). "Influence of Supply Chain Collaborative Innovation on Sustainable Development of Supply Chain: A Study on Chinese Enterprises. Sustainability 2020, 12, 2978.

Storer, M., Ferrer, M. \& Hyland, P. (2007) Innovation in the beef supply chain: the importance of customers and suppliers to innovation. 8th International Continuous Innovation Network Conference. Gothenburg, Sweden, Causal Productions Pty Ltd.4

Song, J. \& Zipkin, P. (2011). Inventory control with Information about Supply Condition, Management Science, 42, 1409-1419.

Soosay, C.A, Hyland, P.W. \& Ferrer, M. (2008). Supply chain collaboration: Capabilities for continuous innovation. Supply Chain Management: An International Journal, 13(2), 160-169.

Tan, K.H., Zhan, Y., Ji, G., Ye, F. and Chang, C. (2015), "Harvesting big data to enhance supply chain innovation capabilities: an analytic infrastructure based on deduction graph", International Journal of Production Economics, Vol. 165, pp. 223-233.

Teece, D.J.; Pisano, G.; Shuen, A. Dynamic capabilities and strategic management. Strateg. Manag. J. 1997, 8,509-533.

Wadhwa, A. and Kotha, S. (2006), "Knowledge creation through external venturing: evidence from the telecommunications equipment manufacturing industry", The Academy of Management Journal, Vol. 49 No. 4, pp. 819-35.

Wagner, S.M. (2010). Supplier traits for better customer firm innovation performance. Industrial Marketing Management, 39(7), 1139-1149.

Watson, N. \& Zhang, Y. (2005). Decentralized serial supply chains subject to order delays and information distortion, Manufacturing and Service Operations Management 7, 152-168.

Wong C.Y., Boon-itt S., Wong C.W.Y.(2011), The contingency effects of environmental uncertainty on the relationship between supply chain integration and operational performance, Journal of Operations Management, 29, 6, 604615.

$\mathrm{Wu}, \mathrm{L} . \mathrm{Y}$. Applicability of the resource-based and dynamic-capability views under environment volatility. J. Bus. Res. 2010, 63, 27-31. 